\title{
Duplex Steels. Part II: Carbides and Nitrides
}

\author{
Marina Knyazeva $\cdot$ Michael Pohl
}

Received: 8 August 2013/Accepted: 25 August 2013/Published online: 3 October 2013

(C) Springer Science+Business Media New York and ASM International 2013

\section{Precipitation Behavior of Duplex Steels}

As mentioned in Part I, duplex stainless steels have a very complex precipitation behavior due to the high amount of alloying elements they contain. Thermodynamically, this leads to the formation of many phases (Fig. 1). Diffusion rates for interstitial elements in ferrite are approximately 100 times higher and have solubilities that are 100 times lower than those in austenite. This leads to the result that formations of carbides, nitrides, and intermetallic phases occur in the ferritic phase only.

The precipitated phases can be distinguished regarding their kinetic formation, controlled due to element solubility or diffusion. The growth of phases, which are dependent on element solubilities, cannot be avoided due to technically practicable cooling rates, in general (austenite, carbides, nitrides, and $\varepsilon$-phase). In contrast, diffusion-dependent phase formation is associated with prolonged treatment time at critical temperatures $\left(\chi\right.$-, $\sigma$-phase, and $475{ }^{\circ} \mathrm{C}$ embrittlement) and can be suppressed by rapidly quenching.

The precipitation behavior of duplex stainless steels shown in Fig. 1 can be divided into two temperature ranges. In the upper temperature range between 600 and $1,000{ }^{\circ} \mathrm{C}$, the nitrides of type $\mathrm{CrN}, \mathrm{Cr}_{2} \mathrm{~N}$, carbides of type $\mathrm{M}_{23} \mathrm{C}_{6}$, and $\chi$ - and $\sigma$-phases can develop. In the lower temperature range of $300-550{ }^{\circ} \mathrm{C}$, the formations of $\pi$-, $\mathrm{Z}$ - and $\alpha^{\prime}$-phases take place $\left(475^{\circ} \mathrm{C}\right.$ embrittlement). In the same temperature range, $\varepsilon$-phase can occur in coppercontaining duplex steels.

M. Knyazeva · M. Pohl ( ()

Fakultät für Maschinenbau, Ruhr-Universität Bochum, Bochum, Germany

e-mail: pohl@wp.rub.de
The solubilities of carbon and nitrogen in duplex steels are limited and become lower with decreasing temperature. Both elements prefer to concentrate in the austenite, due to their higher solubility for interstitial elements and to a greater number of tetrahedral sites. The ferrite can dissolve very small amounts of carbon and nitrogen in octahedral sites and, for this reason, the formations of carbides and nitrides occur exclusively in the ferritic phase and at the ferrite-austenite phase boundaries. An overview of carbides and nitrides, which have been identified in duplex steel by various studies, is shown in Table 1 .

Precipitation of carbides and nitrides greatly reduces the corrosion resistance and toughness of the duplex steels and thus should be avoided. Figures 2, 3, and 4 show examples of the negative effects of carbides and nitrides on corrosion behavior.

\section{Carbides}

The presence of carbon in stainless steel is undesirable because of the formation of chromium carbides, which have a significant negative influence on the corrosion resistance. Carbon is interstitially dissolved in both ferrite and austenite, where its solubility strongly decreases with the decreasing temperature. The fcc lattice of austenite possesses generally a much higher solubility for carbon: for example, an austenitic $18 \mathrm{Cr}-10 \mathrm{Ni}$ steel can dissolve about 0.18 wt. $\%$ at a temperature of $1,100{ }^{\circ} \mathrm{C}$ [12], whereas a ferritic $26 \mathrm{Cr}$ steel can dissolve only $0.05 \mathrm{wt} . \%$ [13].

Studies by Hoffmeister and Mundt [14] and Koch and Eckstein [15] have shown that in ferritic-austenitic duplex steels with carbon contents greater than $0.05 \mathrm{wt} . \%$, the formation of $\mathrm{M}_{23} \mathrm{C}_{6}$ carbides in eutectoid morphology can be observed even after rapid cooling from the annealing 


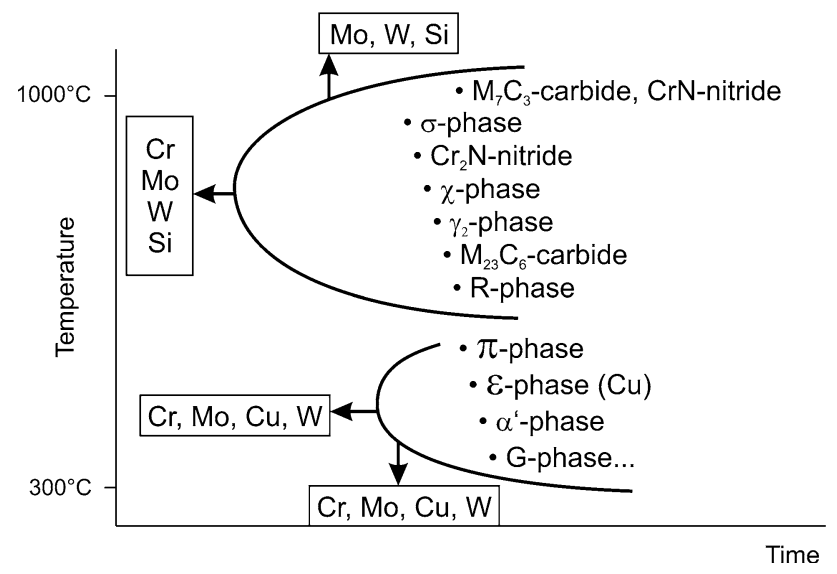

Fig. 1 Precipitation diagram of the duplex stainless steels [1]

temperature. For this reason, the carbon content in commercial low carbon grades is limited to levels of up to 0.05 wt.\%. Prolonged annealing treatment tests of austenitic steels performed by Wiester and Pier [16] have shown that susceptibility to intergranular corrosion disappears only at a carbon content lower than $0.006 \mathrm{wt} . \%$.

Accordingly, the result of water quenching from a solution treatment results in a highly supersaturated carbon solid solution. Because some of the main alloying elements of duplex steels (e.g., chromium and molybdenum) possess a strong affinity for carbon, the tendency to form carbides is high. Precipitation itself is a time- and temperature- dependent process. In the lower temperature range, precipitation is limited by the mobility of carbide-forming elements, whereas the upper limit of the temperature range is determined by the solubility of carbon.

Although in the $\mathrm{Fe}-\mathrm{Cr}-\mathrm{C}$-system, formation of carbides of the types $\mathrm{M}_{23} \mathrm{C}_{6}, \mathrm{M}_{7} \mathrm{C}_{3}$, and $\mathrm{M}_{3} \mathrm{C}$ is possible, in duplex steel, only $\mathrm{M}_{23} \mathrm{C}_{6}$-carbides are generally observed. Therefore, further discussion of carbides in this paper will be confined to this type.

The $\mathrm{M}_{23} \mathrm{C}_{6}$-carbides have a complex face-centered cubic crystal structure, consisting of 92 metal atoms and 24 carbon atoms [3]. Because of its high affinity toward carbon, the main alloying element, chromium, occupies most of the lattice sites which are available for metal atoms. In addition to chromium, other elements such as iron, tungsten, molybdenum, vanadium, manganese, silicon, and nickel can be incorporated in the carbide. Nitrogen, however, is not soluble in it [17]. The chemical composition of the carbide depends on alloy composition on the one hand, and on the annealing temperature and duration of heat treatment on the other.

The temperature range of $\mathrm{M}_{23} \mathrm{C}_{6}$-type chromium carbide precipitation lies between 550 and $1,050{ }^{\circ} \mathrm{C}$; the highest formation rate occurs at about $850^{\circ} \mathrm{C}$. The precipitation rate is very high; thus, the carbides can be observed after a holding time of only one minute at $800{ }^{\circ} \mathrm{C}$ [2].

Carbon has a high affinity for the grain boundaries, which leads to preferred carbide precipitation on the

Table 1 Overview of precipitation phases in duplex stainless steels [2-11]

\begin{tabular}{|c|c|c|c|c|c|}
\hline Phase & Crystal structure & $\begin{array}{l}\text { Lattice parameter } \\
(\mathrm{nm})\end{array}$ & Orientation relation & $\begin{array}{l}\text { Temperature } \\
\text { range }\end{array}$ & Ref \\
\hline $\mathrm{M}_{6} \mathrm{C}$ & Cubic fec $F m 3 m$ & $a=1.128$ & & Up to $1,050{ }^{\circ} \mathrm{C}$ & {$[3,4]$} \\
\hline $\mathrm{M}_{7} \mathrm{C}_{3}$ & Hexagonal Pnma & $\begin{aligned} a & =0.452 \\
b & =0.699 \\
c & =1.211\end{aligned}$ & & $950-1,100{ }^{\circ} \mathrm{C}$ & {$[3,5]$} \\
\hline $\mathrm{M}_{23} \mathrm{C}_{6}$ & Cubic fcc $F m 3 m$ & $a=1.0589-1.0623$ & $\begin{array}{l}\{111\} \gamma\left\|\{333\} \mathrm{M}_{23} \mathrm{C}_{6}\right\|\{110\} \alpha \\
<110>\gamma\left\|<330>\mathrm{M}_{23} \mathrm{C}_{6}\right\|<111>\alpha \\
\{100\} \mathrm{M}_{23} \mathrm{C}_{6} \|\{111\} \gamma \\
<100>\mathrm{M}_{23} \mathrm{C}_{6} \|<111>\gamma \\
\{111\} \gamma \|\{111\} \mathrm{M}_{23} \mathrm{C}_{6} \\
<110>\gamma \|<111>\mathrm{M}_{23} \mathrm{C}_{6}\end{array}$ & $550-1,000{ }^{\circ} \mathrm{C}$ & {$[3,6,7]$} \\
\hline $\mathrm{CrN}$ & Cubic fec $F m 3 m$ & $a=0.414$ & $\begin{array}{l}\{001\} \alpha \|\{001\} \mathrm{CrN} \\
<100>\alpha \|<100>\mathrm{CrN}\end{array}$ & $550-1,000{ }^{\circ} \mathrm{C}$ & {$[3,8]$} \\
\hline $\mathrm{Cr}_{2} \mathrm{~N}$ & Hexagonal $P 31 \mathrm{~m}$ & $\begin{array}{l}a=0.4750-0.4796 \\
c=0.4429-0.4470\end{array}$ & $<0001>\mathrm{Cr}_{2} \mathrm{~N} \|<011>\alpha$ & $550-1,000{ }^{\circ} \mathrm{C}$ & {$[9,10]$} \\
\hline Z-Phase $(\mathrm{FeCr})(\mathrm{NbMo})(\mathrm{CN})$ & Tetragonal P4/nmm & $\begin{array}{l}a=0.6784 \\
c=0.7391-0.7397\end{array}$ & & Up to $1,250^{\circ} \mathrm{C}$ & {$[11]$} \\
\hline$\pi$-Phase $\mathrm{Mo}_{13} \mathrm{Fe}_{7} \mathrm{~N}_{4}$ & Cubic primitive $P 4_{1} 32$ & $a=0.647$ & $\begin{array}{l}\{110\} \alpha \|\{130\} \pi \\
<100>\alpha \|<100>\pi\end{array}$ & $500-600^{\circ} \mathrm{C}$ & {$[10]$} \\
\hline
\end{tabular}




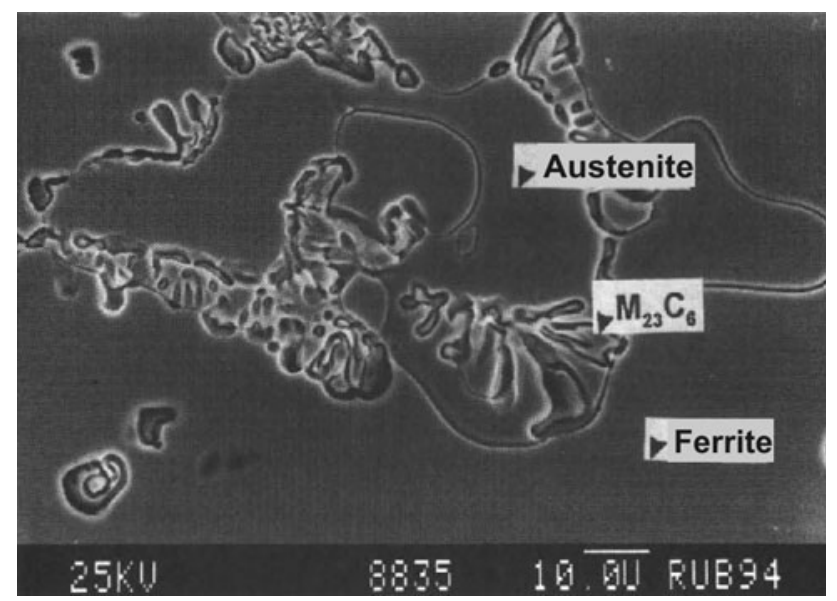

Fig. 2 Corrosion of alloy $27 \mathrm{Cr}-5 \mathrm{Ni}-2 \mathrm{Mo}-0.5 \mathrm{C}$ (DIN 1.4464) after 12-h exposure in nitric acid. Heat treatment: $1,050{ }^{\circ} \mathrm{C} / 2 \mathrm{~h} /$ water

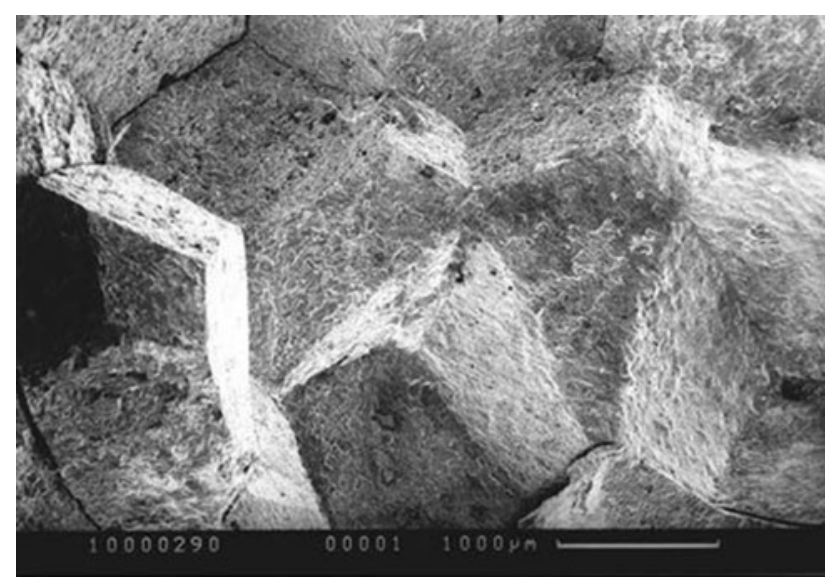

Fig. 3 Intergranular corrosion of alloy $22 \mathrm{Cr}-5 \mathrm{Ni}-3 \mathrm{Mo}-0.2 \mathrm{~N}$ (DIN 1.4462)

ferritic-austenitic phase boundaries $[6,7,17]$. The $\alpha / \gamma$ phase boundaries act as a connection between chromiumrich ferrite and carbon-rich austenite, and have a high defect density as usual. Therefore, they are ideal high energy sites for carbide precipitation. Nevertheless, according to studies by Singhal and Vaidya [7], carbides cannot nucleate at highly ordered, defect-free coherent $\alpha / \gamma$ phase boundaries, which have a Kurdjumov-Sachs orientation. Occasionally, carbide precipitation can occur at dislocations within ferrite grains. This fact underscores the importance of defects for carbides nucleation.

After nucleating from the $\alpha / \gamma$ phase boundary, the carbides grow into the ferrite [6,17-19]. Due to chromium diffusion from the ferrite to carbides, the ferritic lattice becomes unstable and transforms into austenite. At the beginning of growth, ferrite and freshly formed austenite are arranged in a lamellar structure, which means that at
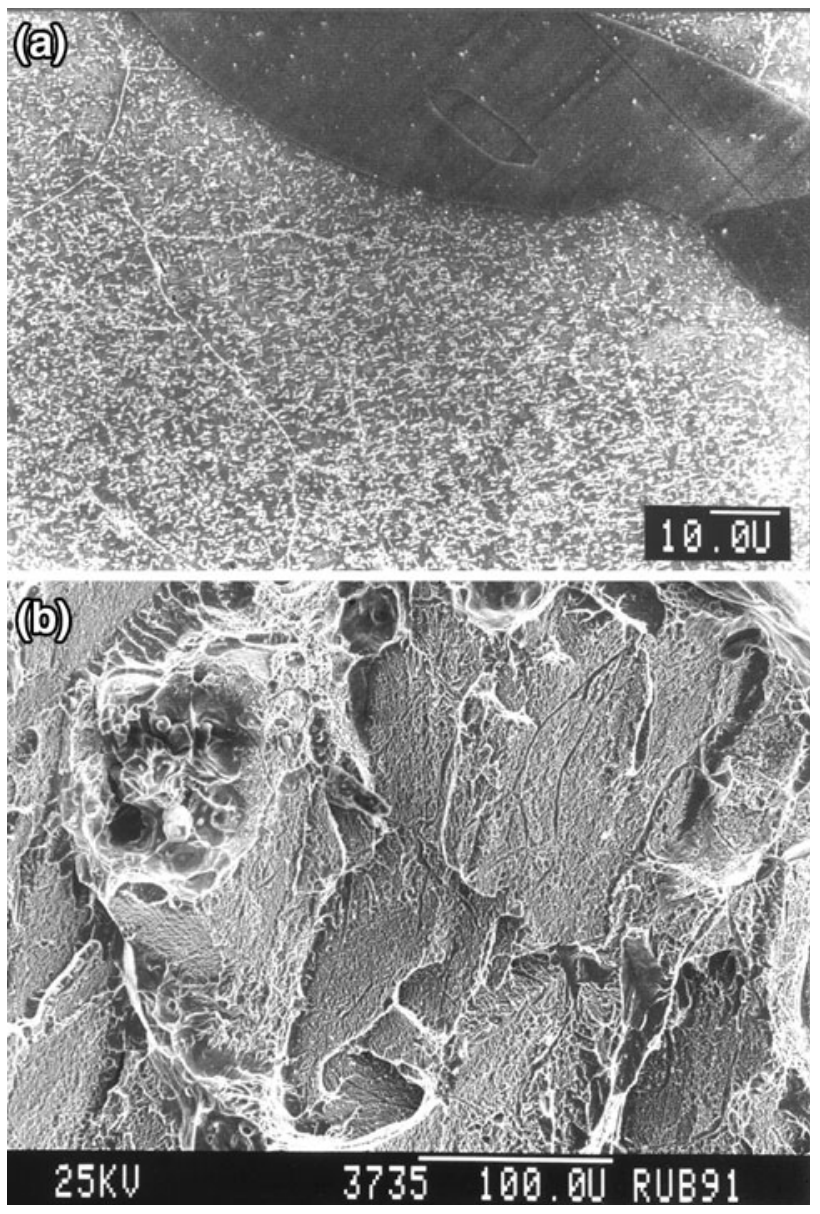

Fig. 4 Casting alloy $26 \mathrm{Cr}-6 \mathrm{Ni}-3 \mathrm{Mo}-3 \mathrm{Cu}-0.2 \mathrm{~N}$. Heat treatment: $1300{ }^{\circ} \mathrm{C} / 2 \mathrm{~h} /$ water quench. (a) Cross section with vein patterns; (b) cleavage fracture caused by chromium nitrides

this stage, growth of carbides takes place by a eutectoid solid-solution transformation [20]:

$\alpha \rightarrow \gamma_{3}+\mathrm{M}_{23} \mathrm{C}_{6}$.

During this transformation, the $\alpha / \gamma$ phase boundary moves between carbide lamellae into the ferrite. The distance between lamellae increases with the increasing annealing temperature [6]. The newly formed austenite $\gamma_{3}$ possesses a significantly lower chromium content of about $14 \mathrm{wt} . \%$, and has the same orientation as the austenite, which is where the carbides originated $[6,18]$.

The advanced stage of carbide growth requires more chromium than can be delivered by the transformation of austenite into ferrite between the carbide lamellae. This leads to migration of the $\alpha / \gamma$ phase boundary further into the ferrite, so that finally, the carbides lie completely in austenite (Fig. 5).

The phase boundary is the natural connection between the high-chromium ferritic phase and the carbon-rich austenitic phase. Consequently, most of the chromium required for carbide formation comes from the ferritic 

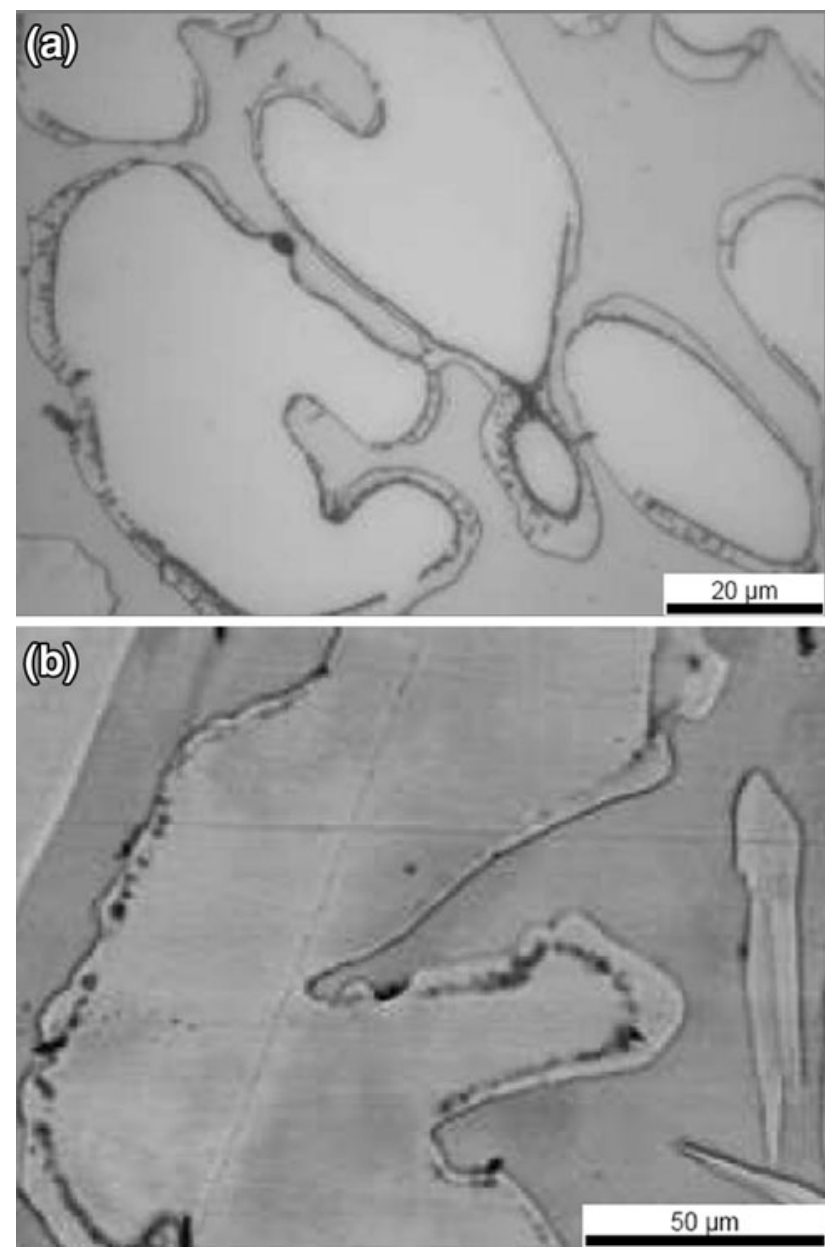

Fig. 5 Micrograph and backscattered electron image of the duplex steel $26 \mathrm{Cr}-6 \mathrm{Ni}-3 \mathrm{Mo}-3 \mathrm{Cu}-0.2 \mathrm{~N}$. Heat treatment: $850{ }^{\circ} \mathrm{C}$ for $6 \mathrm{~min} /$ water quench

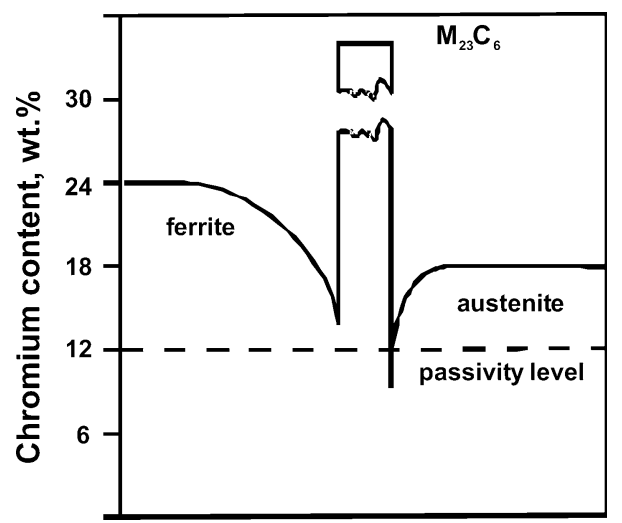

Fig. 6 Schematic representation of the chromium concentration profile in duplex steel at the $\alpha / \gamma$ phase boundaries with $\mathrm{M}_{23} \mathrm{C}_{6}$ carbide precipitation

phase. This results in formation of a wide chromiumdepleted area in the ferrite (Fig. 6). At the same time, a narrow, but strongly chromium-depleted zone results in the

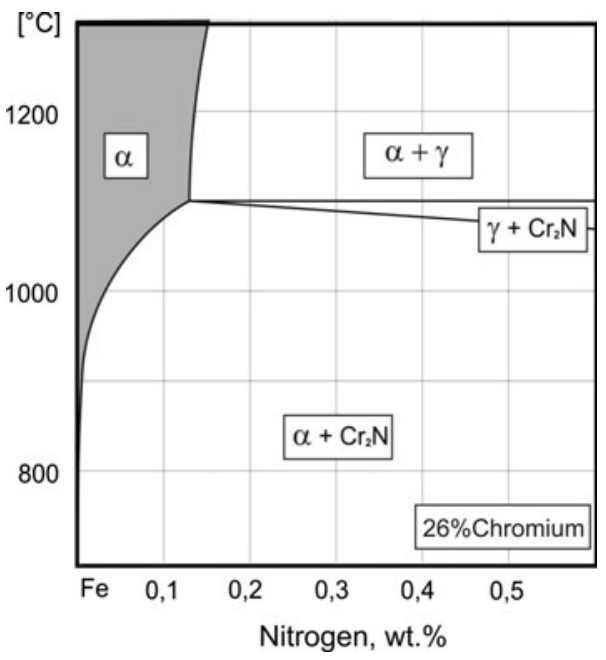

Fig. 7 Quasy binary section through the phase diagram for $\mathrm{Fe}-\mathrm{Cr}-\mathrm{N}$ at 26 wt.\% $\mathrm{Cr}[22]$

austenite due to a lower diffusion rate. This increases the sensitivity for intergranular corrosion, which can take place on the austenitic phase boundary.

\section{Nitrides}

The main purpose of alloying ferritic-austenitic duplex steels with nitrogen is to increase the yield strength and the resistance to pitting corrosion. The pitting resistance equivalent (PRE) shows the positive influence of nitrogen on the corrosion behavior of steels: unlike the element chromium, which is calculated with a factor of unity 1 in the PRE formula, nitrogen usually receives a factor between 16 and 30. Besides the higher corrosion resistance, the dissolved nitrogen produces an increase in the yield strength, which facilitates construction of thin-walled components. Furthermore, the addition of nitrogen causes short-range ordering, which means that a clustering of atoms, and therefore nucleation and precipitation, is inhibited. As a result, dissolved nitrogen delays the formation of intermetallic phases, in particular $\chi, \sigma$ and $\alpha^{\prime}$. Nitrogen stabilizes the austenite, and so extends the field of ferritic-austenitic stability. Coarsening of the ferrite can also be delayed by nitrogen [21].

A precondition for the positive effect of nitrogen is its complete solution in the lattice sites. Therefore, formation of any nitride precipitates must be avoided. In comparison with carbon, a nitrogen atom has a smaller diameter, allowing a higher solubility in both the austenite and the ferrite. The solubility of nitrogen in ferritic-austenitic steels can be enhanced by increasing the chromium content (Fig. 7). Simultaneously, the tendency for chromium nitride formation is reinforced, and this limits the 


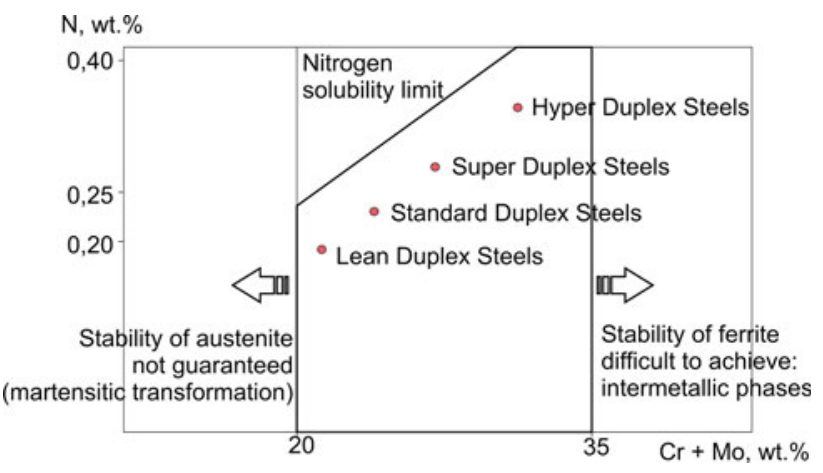

Fig. 8 Development of conventional duplex stainless steels [23]

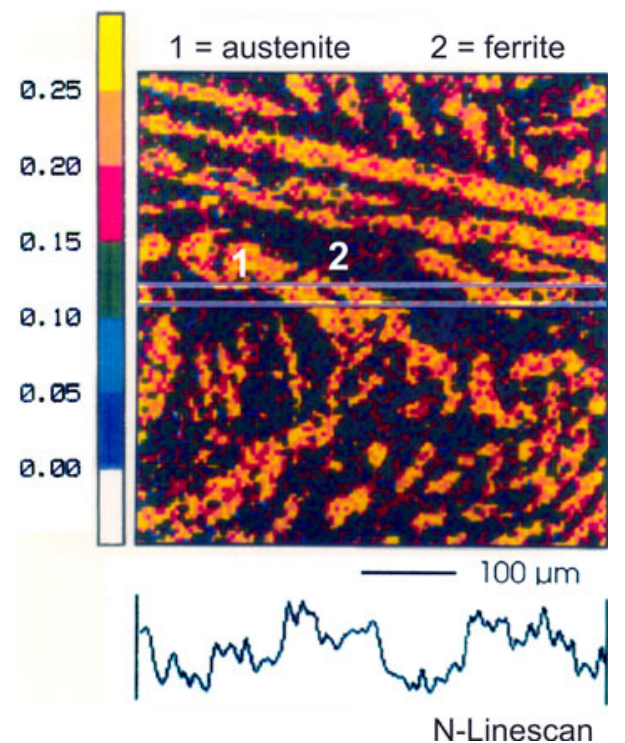

Fig. 9 Nitrogen concentration mapping with WDX

maximum chromium and nitrogen contents that can be added to duplex steels. Figure 8 illustrates a schematic overview of the development of duplex stainless steels in terms of the ratio of chromium to nitrogen content.

In duplex stainless steels, the largest nitrogen fraction is dissolved in the austenite (Fig. 9). Precipitation of nitrides, however, takes place only in the ferrite and at its phase boundary. The reason for this is that the diffusion processes proceed faster and the solubility of nitrogen in the ferrite is substantially lower than that in the austenite. Formation of nitrides can be distinguished by their different precipitation mechanisms into the two nitride compounds, $\mathrm{CrN}$ and $\mathrm{Cr}_{2} \mathrm{~N}$.

\section{CrN}

At temperatures below $1,000{ }^{\circ} \mathrm{C}$, the ferrite exhibits a reduction in nitrogen solubility (Fig. 10). If duplex steels are exposed at very high annealing temperatures and rapidly quenched, then this can lead to formation of $\mathrm{CrN}$ in the

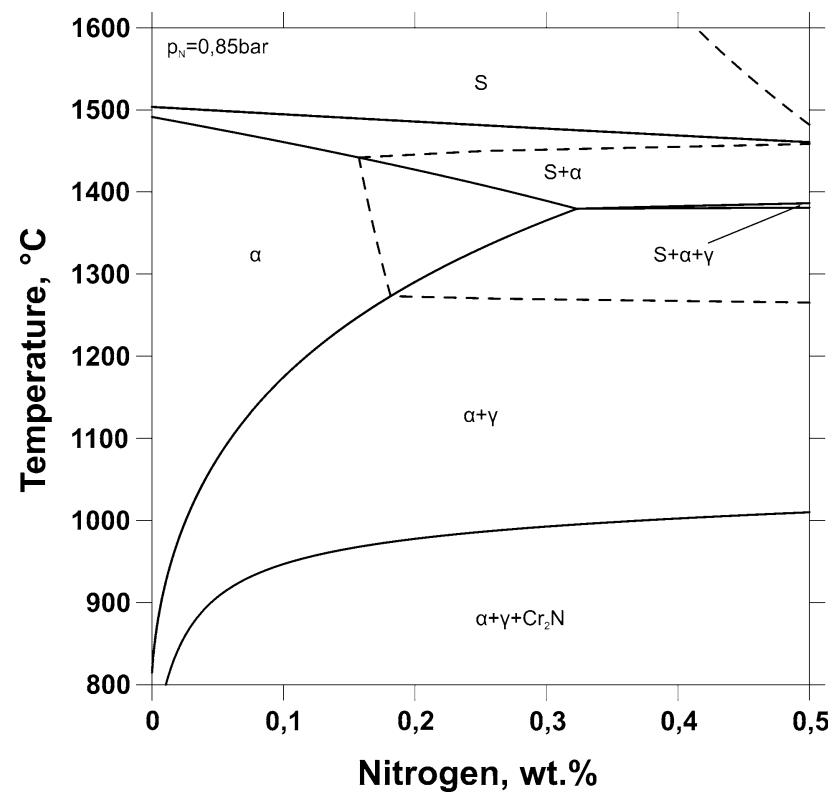

Fig. 10 Solubility of nitrogen in duplex stainless steel, as a function of temperature

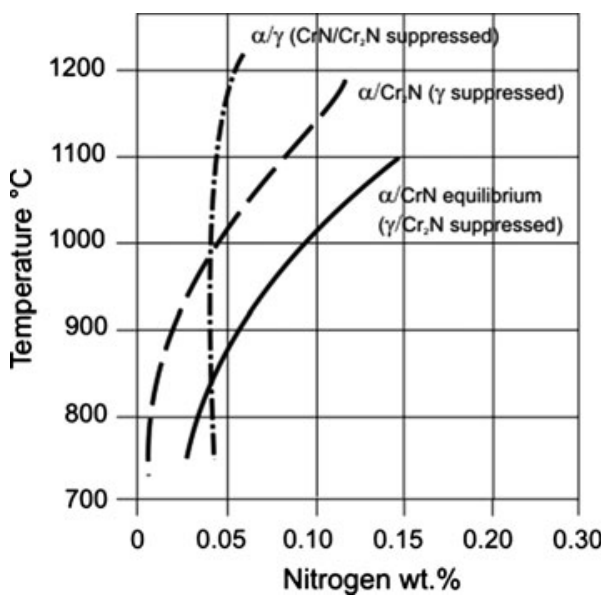

Fig. 11 Solubility equilibria of different phases in ferrite as a function of temperature [24]

ferritic phase. For example, such conditions are common in the heat-affected zone of welds. Hertzman et al. [24] found such precipitates in welds of duplex steel 2205.

$\mathrm{CrN}$ nitride is formed when the nitrogen solubility is exceeded, and, at the same time, the diffusion of excess nitrogen into the austenite is hindered. The free enthalpy, which represents the driving force for nucleation, is higher for $\mathrm{CrN}$ than for $\mathrm{Cr}_{2} \mathrm{~N}$ at temperatures below $1,000{ }^{\circ} \mathrm{C}$ [25]. Thermodynamic analysis of nitride solubility in ferrite revealed that $\mathrm{CrN}$ precipitates before the more stable equilibrium phase $\mathrm{Cr}_{2} \mathrm{~N}$ (in a situation where the cooling rate is so high that the precipitation of austenite and $\mathrm{Cr}_{2} \mathrm{~N}$ can be suppressed) (Fig. 11). The reason for this is the lower activation energy for nucleation of $\mathrm{CrN}$ due to its close similarity 


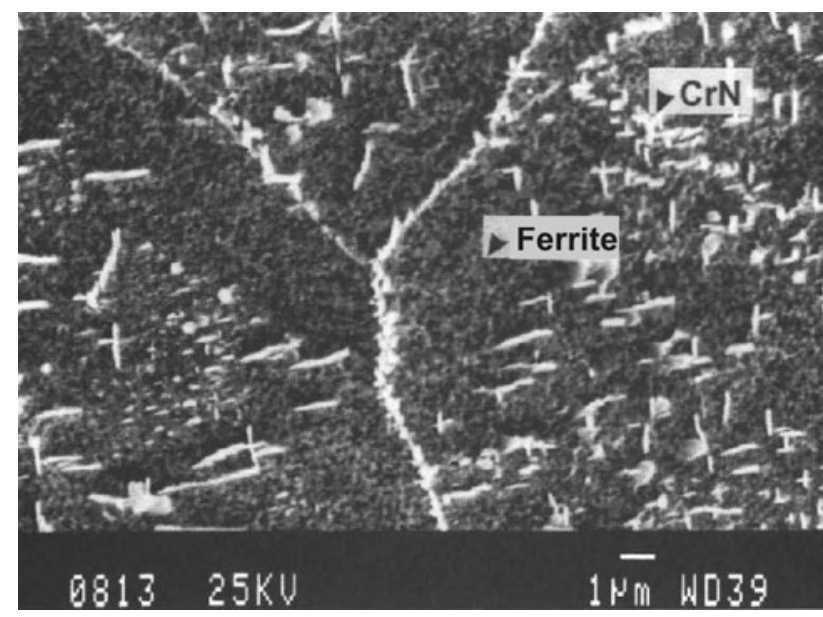

Fig. 12 Precipitation of chromium nitrides of type $\mathrm{CrN}$ in the alloy $26 \mathrm{Cr}-6 \mathrm{Ni}-3 \mathrm{Mo}-3 \mathrm{Cu}-0.2 \mathrm{~N}$ after water quenching from $1,250{ }^{\circ} \mathrm{C}$ [2]

to the ferrite lattice. The crystal structure of the $\mathrm{CrN}$ nitride type is primitive cubic, in contrast to the hexagonal $\mathrm{Cr}_{2} \mathrm{~N}$ nitride. $\mathrm{CrN}$ has a plate-shaped configuration and is crystallographically orientated to the $\{001\}$ cube planes of ferrite, because of a close match in lattice parameter [8].

Because precipitation of $\mathrm{CrN}$ occurs when the nitrogen solubility is exceeded, this nitride type cannot be suppressed even at cooling rates $>2,500{ }^{\circ} \mathrm{C} / \mathrm{s}$. Wischnowski [2] quenched rapidly razor-thin metal sheets in ice water from a temperature of $1,250{ }^{\circ} \mathrm{C}$. As a result, homogeneously dispersed disk-shaped $\mathrm{CrN}$ nitrides formed in the ferrite (Fig. 12). Their formation is attributed to the fact that an increasing annealing temperature is associated with a reduction of the austenite/ferrite ratio. While austenite is dissolving, some of the nitrogen diffuses into the remaining austenite. The remainder of the nitrogen stays in the ferrite. The solubility of nitrogen above $1,100{ }^{\circ} \mathrm{C}$ increases exponentially with temperature (Fig. 7). At temperatures of $1,200{ }^{\circ} \mathrm{C}$ and higher, the concentration of nitrogen in the ferrite is so high that nitrogen cannot be kept in solution, even by ice water quenching.

\section{$\mathrm{Cr}_{2} \mathbf{N}$}

Nitrides of type $\mathrm{Cr}_{2} \mathrm{~N}$ have about the same formation enthalpy as carbides of type $\mathrm{M}_{23} \mathrm{C}_{6}$, so that their precipitation occurs simultaneously in the same temperature interval of $550-1,000{ }^{\circ} \mathrm{C}$ [26]. The kinetics is the highest in the temperature range of $700-900{ }^{\circ} \mathrm{C}$. This nitride of type $\mathrm{Cr}_{2} \mathrm{~N}$ has an hexagonal crystal structure and a low coherency with the basic lattices of ferrite and austenite. This leads to precipitation of plate-shaped $\mathrm{Cr}_{2} \mathrm{~N}$ on the ferriticaustenitic phase boundaries or on low angle grain boundaries [27] in the ferrite. Schwaab [26] has also detected the
$\mathrm{Cr}_{2} \mathrm{~N}$ precipitates within the ferrite matrix after long annealing times.

According to studies by Eriksson [9], the range of nitrogen content of $\mathrm{Cr}_{2} \mathrm{~N}$ nitride is from 9.3-11.9 wt.\%. Chromium is present with a value of $71.5 \mathrm{wt} . \%$, molybdenum with $6.0 \mathrm{wt} . \%$, and nickel with $1.1 \mathrm{wt} . \%$ [10]. Due to the high chromium and nitrogen contents, this precipitation strongly decreases pitting corrosion resistance.

The fact that the size and amount of nitrides is independent of the treatment time suggests that precipitation does not take place during the annealing treatment, but at lower temperatures [24].

\section{$\pi$ and Z-Phase}

The formation of the $\pi$-phase in duplex stainless steels occurs in the temperature range of $500-600{ }^{\circ} \mathrm{C}[10]$. It is a nitride with primitive cubic structure, which is stable in the ternary systems $\mathrm{Cr}-\mathrm{Ni}-\mathrm{N}$ and $\mathrm{Cr}-\mathrm{Mo}-\mathrm{N}$, and in the quaternary system $\mathrm{Cr}-\mathrm{Fe}-\mathrm{Ni}-\mathrm{N}$ [10, 28, 29]. Chemical analysis of the metallic component of the $\pi$-phase revealed the following composition: $28 \mathrm{wt} . \% \mathrm{Fe}, 35 \mathrm{wt} . \% \mathrm{Cr}, 34 \mathrm{wt} . \%$ Mo, and 3 wt.\% Ni [10].

The Z-phase is a carbonitride compound, $[(\mathrm{FeCr})(\mathrm{Nb}-$ $\mathrm{Mo})](\mathrm{CN})$, with $\mathrm{M}_{2} X$-type stoichiometry and a tetragonal lattice structure. The Z-phase only occurs in unstabilized niobium-containing steels with low carbon and high nitrogen contents $[8,11,30,31]$. In these alloys, the $\mathrm{NbC}$ carbide and $\mathrm{NbN}$ nitride can arise from the melt according to solubility equilibrium. Both phases can intermingle as solid solution crystal and the stable mono-carbonitride, $\mathrm{Nb}(\mathrm{CN})$, will be formed from the melt. As carbon is depleted from the melt, the niobium will react with available nitrogen and form the Z-phase, whereby the carbonitride can also be partially transformed into Z-phase. According to studies by Gerlach and Schmidtmann [30] and Bäumel [31], the Z-phase is extremely stable and can be dissolved only at temperatures above $1,250{ }^{\circ} \mathrm{C}$.

\section{Technical Importance and Prevention}

The precipitation of $\mathrm{CrN}$ as well as of $\mathrm{Cr}_{2} \mathrm{~N}$ nitrides in the ferrite leads to constrained deformation behavior and, at least, to brittle fracture behaviour of the duplex stainless steels. The brittle fracture of tensile or impact test specimen shows surfaces with a cleavage in $\{100\}$ plane along the precipitated $\mathrm{Cr}_{2} \mathrm{~N}$ nitrides (Fig. 13). In a bending test, highly localized deformation can occur on the surface of the bend specimen (Fig. 14). These deformation bands run in the form of planar slip in the $<111>$ direction along a 


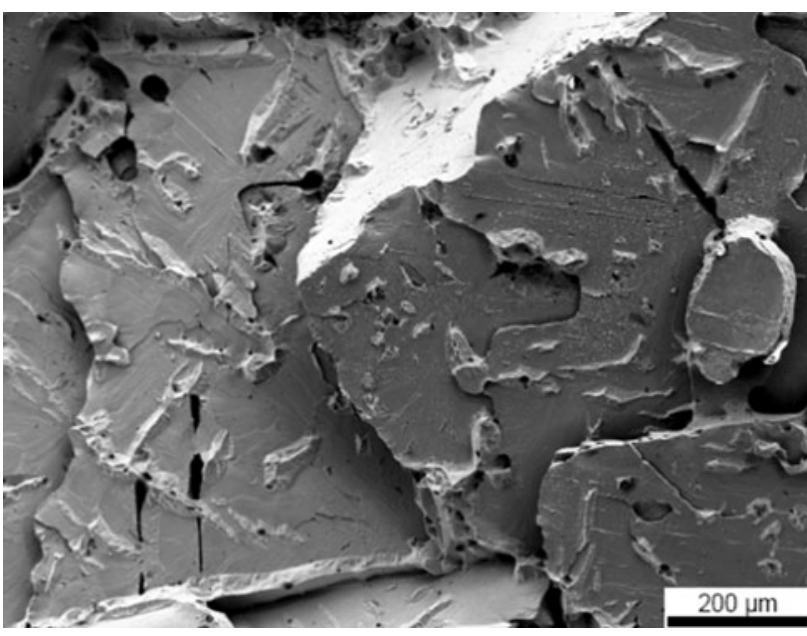

Fig. 13 Cleavage fracture in a nitride-affected duplex steel

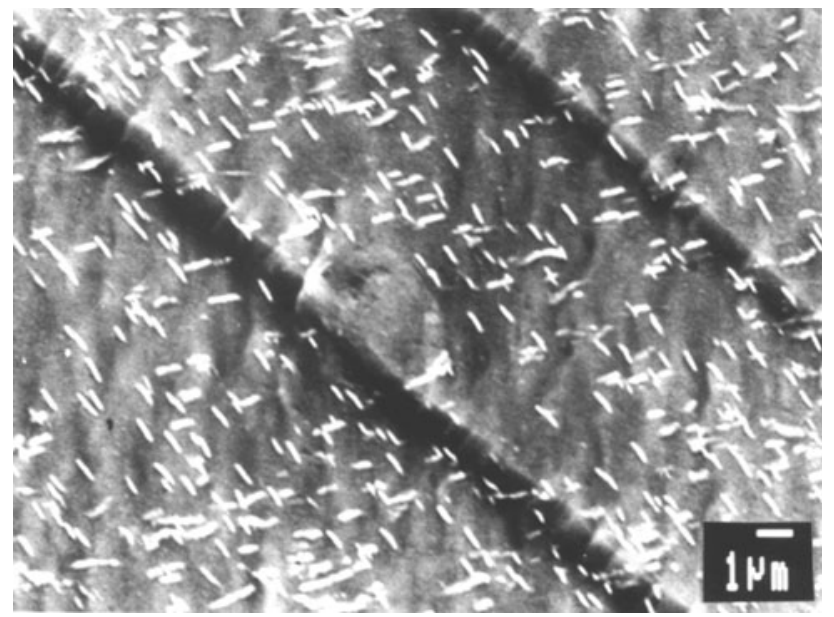

Fig. 14 Nitride embrittlement $(\varepsilon=5 \%)$ : planar slip in the ferritic phase ("slipping to death") $26 \mathrm{Cr}-6 \mathrm{Ni}-3 \mathrm{Mo}-3 \mathrm{Cu}-0.2 \mathrm{~N}$. Heat treatment: $1300{ }^{\circ} \mathrm{C} / 2 \mathrm{~h} /$ water quench

few lattice planes. Both failure modes are undesirable and, for this reason, nitride precipitations should be avoided.

Both carbides and nitrides in duplex steel should be avoided in order to maintain optimum physical and mechanical properties. Precipitation of carbides can be prevented by limiting carbon content to a maximum of $0.05 \mathrm{wt} . \%$. In order to prevent the precipitation of unwanted phases, quenching from annealing temperature should take place as rapidly as possible. However, because of the low solubility of nitrogen in ferrite, nitride precipitates of type $\mathrm{CrN}$ cannot be avoided by quenching from high temperatures, even with the highest cooling rate.

A technical solution to this problem can be achieved taking advantage of the greatly reduced nitrogen solubility in ferrite with decreasing temperature, and allowing nitrogen to diffuse from the ferrite into the austenite.

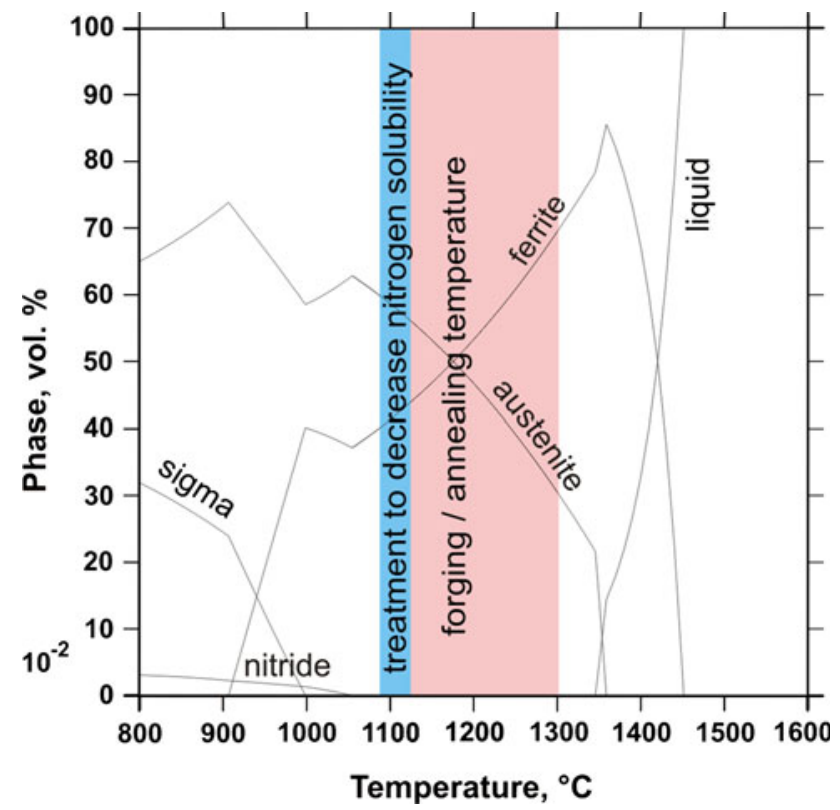

Fig. 15 Phase diagram for the alloy $25 \mathrm{Cr}-7 \mathrm{Ni}-3 \mathrm{Mo}-\mathrm{Cu}-0.26 \mathrm{~N}$, with schematic representation of heat-treatment temperatures

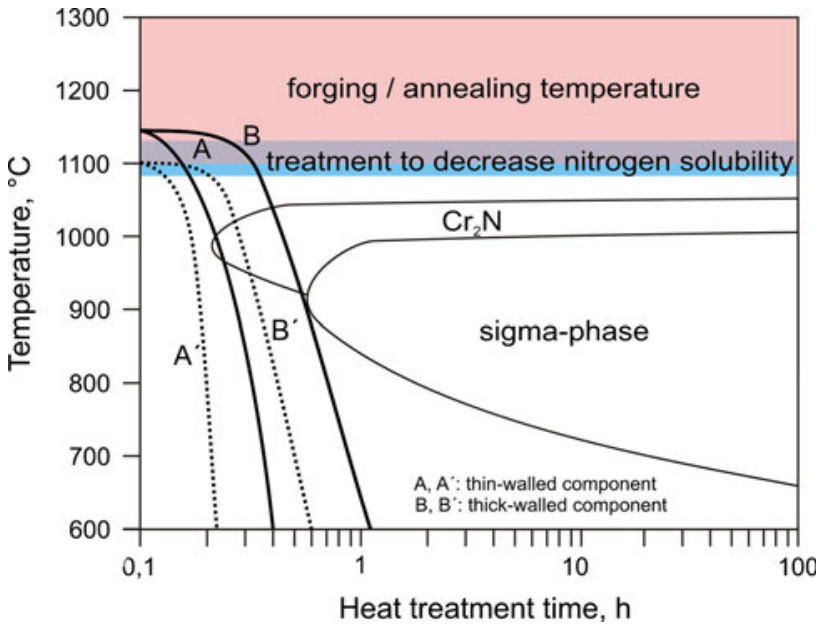

Fig. 16 Schematic representation of the heat treatment of thin- and thick-walled components

Nitrogen is soluble in austenite in large concentrations and therefore does not tend to form precipitates even at lower temperatures. For this reason, the material must be cooled slowly from the forging or annealing temperature to a lower temperature with decreased nitrogen solubility. This lower temperature has to differ by about $50{ }^{\circ} \mathrm{C}$ from thermodynamic equilibrium of the $\mathrm{Cr}_{2} \mathrm{~N}$ nitrides (Fig. 15).

However, the production of precipitation-free duplex steel is not only dependent on annealing conditions, but also on cooling rate, which is limited by the component thickness (Fig. 16). Quenching from annealing temperatures that are too high causes $\mathrm{CrN}$ and $\mathrm{Cr}_{2} \mathrm{~N}$ precipitation in the entire component (cooling curves $\mathrm{A}$ and $\mathrm{B}$ ). The cooling of 
thin-walled components from the treatment step to decrease the nitrogen solubility helps in suppressing precipitation completely (cooling curve $\mathrm{A}^{\prime}$ ), but for thick-walled components $\mathrm{Cr}_{2} \mathrm{~N}$ precipitation at mid-wall is still unavoidable (cooling curve $\mathrm{B}^{\prime}$ ). Carbides, as well as nitride precipitation, can be dissolved by reheating to temperatures higher than the annealing treatment conditions of about $1,050-1,100{ }^{\circ} \mathrm{C}$.

\section{Conclusion}

The large fraction of alloying elements in ferritic-austenitic duplex stainless steels leads to the formation of many phases. Precipitations of carbides, nitrides, and intermetallic phases occur only in the ferritic phase. In Part II of this study, the precipitations of carbides and nitrides have been considered. At temperatures between 600 and $1,000{ }^{\circ} \mathrm{C}$ carbide and nitride precipitations of types $\mathrm{CrN}, \mathrm{Cr}_{2} \mathrm{~N}$, and $\mathrm{M}_{23} \mathrm{C}_{6}$ take place. At lower temperatures between 500 and $600{ }^{\circ} \mathrm{C}$, the $\pi$ - and Z-phases can be expected to precipitate.

Carbides as well as nitrides lower the corrosion resistance significantly and cause a brittle material failure. Therefore, the formation of carbides and nitrides should be avoided in general. This can be achieved by limited carbon content of maximal 0.05 wt. $\%$ and by quenching from annealing temperature as rapidly as possible. In this way, the diffusion-dependent formation of carbides and $\mathrm{Cr}_{2} \mathrm{~N}$ nitride is prevented.

The nitride formation of type $\mathrm{CrN}$, however, is associated with the temperature-dependent nitrogen solubility in the ferritic phase. If the limit of nitrogen solubility in ferrite is exceeded, then $\mathrm{CrN}$-precipitation occurs, and it cannot be suppressed even by higher cooling rates. Using an appropriate heat treatment, at which the nitrogen can diffuse from the ferrite to the austenite, this problem can be solved. This helps to prevent the nitride precipitation on thin-walled components even for super duplex steels with high nitrogen and chromium contents. For thick-walled components of super duplex steels, the precipitations cannot be avoided because of the technically limited cooling rates. Therefore, it is recommended that we take the toughness and corrosion resistance values as additional admission criteria. If carbides or nitrides are already precipitated, then reheating to the annealing temperature can be employed to dissolve them.

\section{References}

1. J. Charles, Super duplex stainless steels: structure and properties, in Proceedings of the Conference on Duplex Stainless Steels '91, Beaune (1991), pp. 3-48

2. F. Wischnowski, Effect of microstructural modifications on the corrosion resistance of stainless ferritic-austenitic duplex steels, Dissertation, Ruhr-Universität, Bochum (1995)
3. W.B. Pearson, A Handbook of Lattice Spacings and Structures of Metals and Alloys (Pergamon Press, Oxford, 1958)

4. H.W. Müller-Stock, Influence of heat treatment on the mechanical properties of the ferritic-austenitic steels X 8 CrNiMo 275 and X4 CrNiMoNb 25 7. TEW-Tech. Rep. 1, 47-54 (1976)

5. H.D. Solomon, Age hardening in a duplex stainless steel, in Proceedings of the Conference on Duplex Stainless Steels '86, The Hague (1986), pp. 41-69

6. F.R. Beckitt, The formation of sigma-phase from delta-ferrite in a stainless steel. J. lron Steel Inst. 207, 632-638 (1969)

7. I.K. Singhal, M.I. Vaidya, Precipitation of sigma phase in a duplex Fe-Cr-Ni-Ti alloy. Trans. ASM 62, 879-885 (1969)

8. G. Tacke, H.-J. Köhler, Precipitation behavior of stainless ferritic-austenitic steels with high molybdenum contents. Steel Res. 58(3), 123-128 (1987)

9. S. Erikson, Radiographic examination of the system iron-chromium-nitrogen. Jernkontorets Annaler 118, 530-543 (1934)

10. J.-O. Nilsson, P. Llu, Aging at $400-600{ }^{\circ} \mathrm{C}$ of submerged arc welds of $22 \mathrm{Cr}-3 \mathrm{Mo}-8 \mathrm{Ni}$ duplex stainless steel and its effect on toughness and microstructure. Mater. Sci. Technol. 7, 853-862 (1991)

11. H. Huges, Complex nitride in $\mathrm{Cr}-\mathrm{Ni}-\mathrm{Nb}$ steels. J. Iron Steel Inst. 205, 775-778 (1967)

12. H. Tuma, M. Vyklicky, K. Löbl, Carbon activity and solubility in austenitic stainless steels with $18 \% \mathrm{Cr}$. Arch. Eisenhüttenwesen 41(10), 983-988 (1970)

13. K. Bungardt, E. Kunze, E. Horn, Influence of various alloying elements on the $\gamma$-field in the system of iron-chromium-carbon. Arch. Eisenhüttenwesen 39(11), 863-867 (1968)

14. R. Hoffmeister, R. Mundt, Investigation of the influence of carbon and nitrogen on the $\delta$ - $\gamma$-transphormation of ferritic-austenitic steels. Arch. Eisenhüttenwesen 52(4), 159-164 (1981)

15. U. Koch, H.J. Eckstein, On issues of ferritization behavior and adjustment of the phase ratio in ferritic-austenitic stainless steels. Neue Hütte 23(1), 9-12 (1978)

16. H.-J. Wiester, G. Pier, Investigations on the intergranular corrosion of austenitic stainless steels after prolonged treatment at $450^{\circ}-800{ }^{\circ} \mathrm{C}$. Arch. Eisenhüttenwesen 30(5), 293-297 (1959)

17. P.D. Southwick, R.W.K. Honeycombe, Precipitation of $\mathrm{M}_{23} \mathrm{C}_{6}$ at austenite/ferrite interfaces in duplex stainless steel. Metal Sci. 16(10), 475-481 (1982)

18. C.S. Tendom, D.A. Vermilyea, Some observation on carbide precipitation and grain boundary migration in a duplex stainless steel. Metall. Trans. 1(7), 2043-2046 (1970)

19. T.M. Devine, Kinetics of sensitization and de-sensitization on duplex 308 stainless steel. Acta Metall. 36(6), 1491-1501 (1988)

20. T.M. Devine, Influence of carbon content and ferrite morphology on sensitization of duplex stainless steels. Metall. Trans. A 11(5), 791-800 (1980)

21. M. Pohl, Application and failure mechanisms of stainless ferriticaustenitic duplex steels. Stainless steels in the power plant and plant engineering, in Proceedings of the 6th Conference on Failure Analysis, VDI-Reports, vol. 1150 (1994), pp. 27-50

22. J. Charles, 10 years later, obviously duplex grades in industrial applications look like a success story, in Proceedings of the Conference on Duplex Stainless Steels 2000, Venezia (2010), pp. $1-12$

23. L. Brewer, C. Shih-Ger, Construction of ternary alloys, in Metals Handbook, vol. 8, 8th edn., ed. by T. Lyman (American Society for Metals, Materials Park, 1973), pp. 421-425

24. S. Hertzman, W. Roberts, M. Lindenmo, Microstructure and properties of nitrogen alloyed duplex stainless steel weld metal, in Proceedings of the Conference on Duplex Stainless Steels '86, The Hague (1986), pp. 257-267

25. R.F.A. Jargelius-Pettersson, S. Hertzman, P.J. Ferreira, The influence of microstructure on pitting corrosion in autogenous 
TIG duplex stainless steel welds, in Proceedings of the Conference on Duplex Stainless Steels '94, Glasgow (1994)

26. P. Schwaab, Precipitation behavior of the ferritic-austenitic steel $\mathrm{X} 2 \mathrm{CrNiMoN22-5-3}$, in Proceedings of the Conference on Progress in Metallography (Special Editions of Practical Metallography), vol. 14 (1983), pp. 435-444

27. I.-E. Svensson, B. Gretoft, Properties-microstructure relationship for duplex stainless steel weld metals, in Proceedings of the Conference on Duplex Stainless Steels '86, The Hague (1986), pp. $288-294$

28. K.A. Frisk, A thermodynamic evaluation of the $\mathrm{Cr}-\mathrm{Fe}-\mathrm{Ni}-\mathrm{N}$ system. Mater. Res. 82(2), 108-117 (1991)
29. M. Kajihara, N. Ono, M. Kikuchi, Formation and stability of a nitride with the structure of $\beta$-manganese in the $\mathrm{Cr}-\mathrm{Ni}-\mathrm{N}$ ternary and $\mathrm{Cr}-\mathrm{Fe}-\mathrm{Ni}-\mathrm{N}$ quaternary systems, in Proceedings of the Conference on High Nitrogen Steels, Kiev (1993), pp. 63-72

30. H. Gerlach, E. Schmidtmann, Influence of carbon, nitrogen and boron on the precipitation behavior of an austenitic steel with $16 \% \mathrm{Cr}, 2 \% \mathrm{Mo}, 16 \% \mathrm{Ni}$, and niobium. Arch. Eisenhüttenwesen 39(2), 139-149 (1968)

31. A. Bäumel, Correlation between precipitation and corrosion behavior of niobium stabilized steels with $17 \% \mathrm{Cr}$. Steel and Iron 85(22), 1462-1476 (1965) 